Supporting Information

\title{
Langmuir-Blodgett Films Constructed from a Charge-Transfer Complex and Gold Nanoparticles
}

Yoko Tatewaki, Yuki Noda, Ryo Tunashima, Tomoyuki Akutagawa, Takayoshi Nakamura, Hiroyuki

Hasegawa, Shinro Mashiko, and Jan Becher

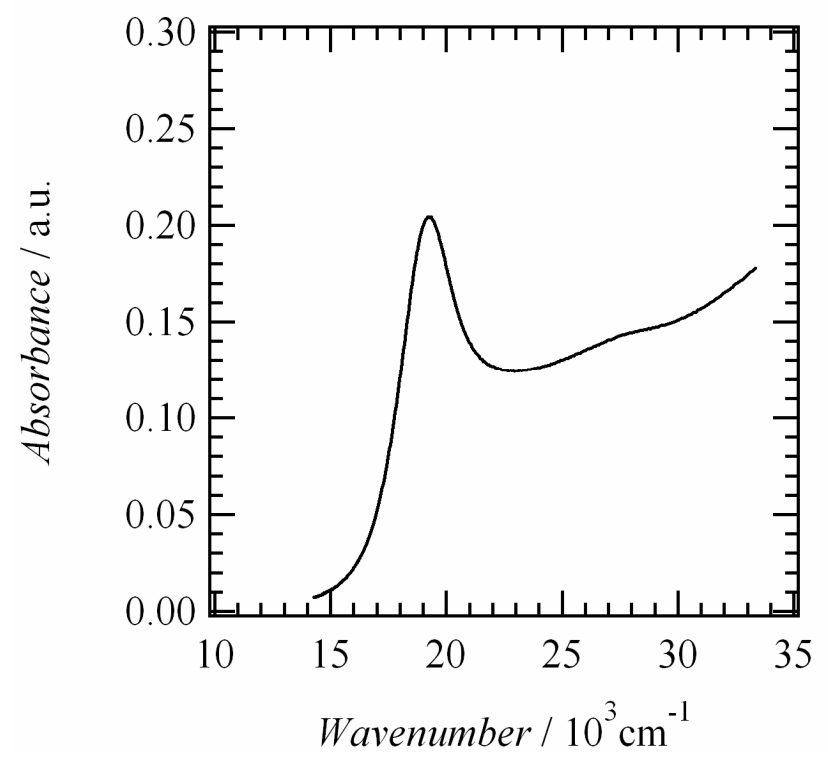

Figure S1. UV-vis spectrum of gold nanoparticle with an average diameter of $13 \mathrm{~nm}$ in $\mathrm{H}_{2} \mathrm{O}$. 

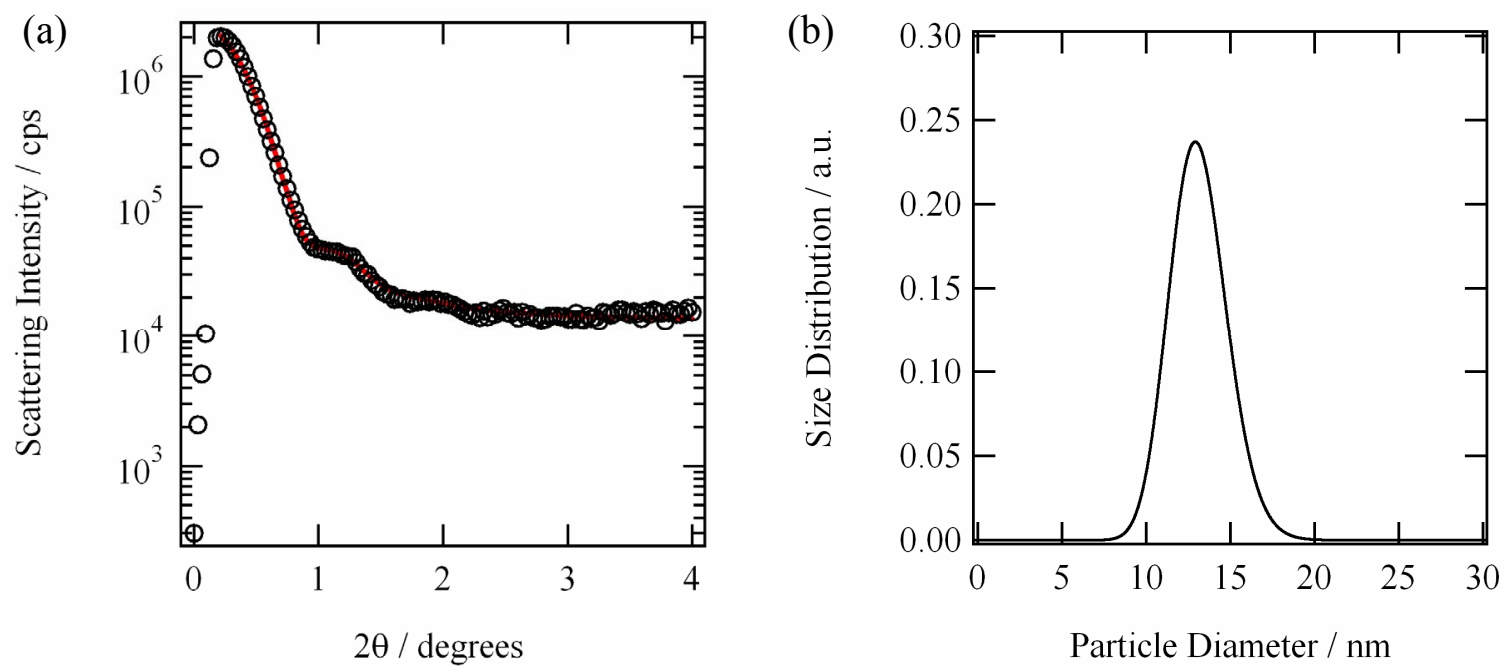

Figure S2. X-ray small angle scattering of gold nanoparticles in $\mathrm{H}_{2} \mathrm{O}$. a) $2 \theta$ vs. scattering intensity profile with a transmittance optical configuration. Red-line is a fit by a spherical model. b) Size distribution of the diameter of gold nanoparticles. The average diameter and normalized variance were $13.4 \mathrm{~nm}$ and $14.2 \%$, respectively.

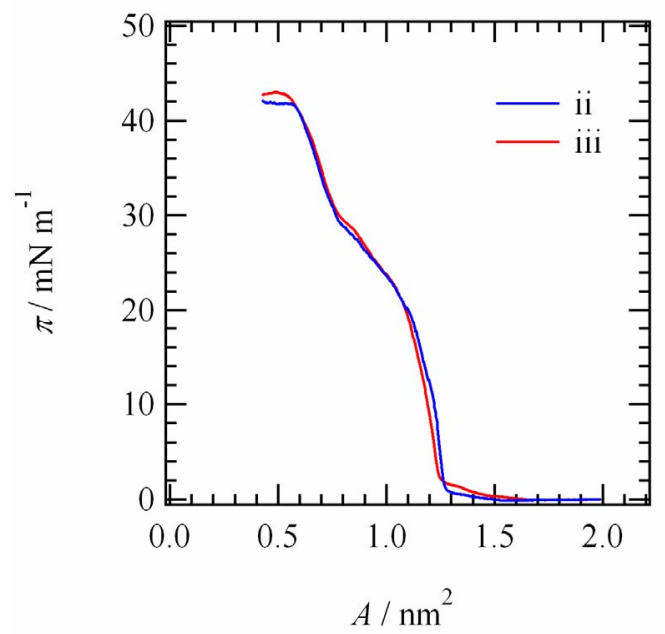

Figure S3. The $\pi-A$ isotherms of $\left(\mathbf{1}^{2+}\right)\left(\mathrm{F}_{4}-\mathrm{TCNQ}^{-}\right)_{2}$ in a $10 \mathrm{mM} \mathrm{KCl}$ subphase (i) containing gold nanoparticles at $c_{\mathrm{Au}}=1 \times 10^{-5}$ and (ii) $c_{\mathrm{Au}}=1 \times 10^{-6}$. 
a)

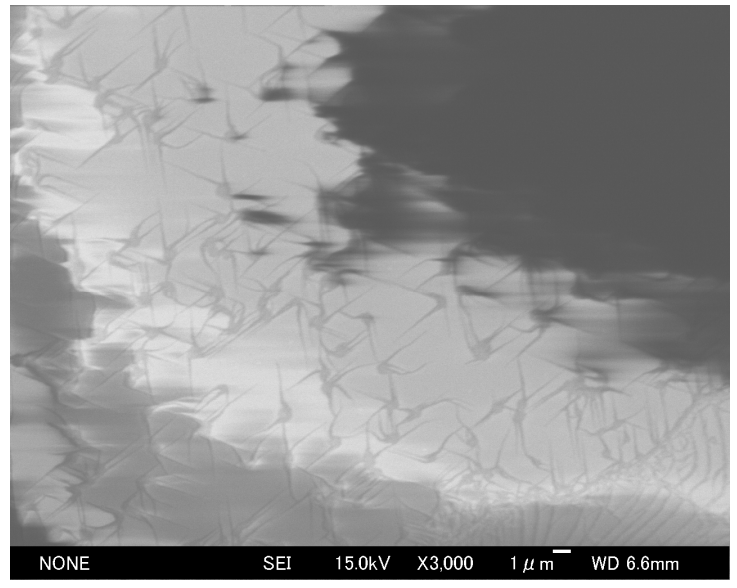

c)

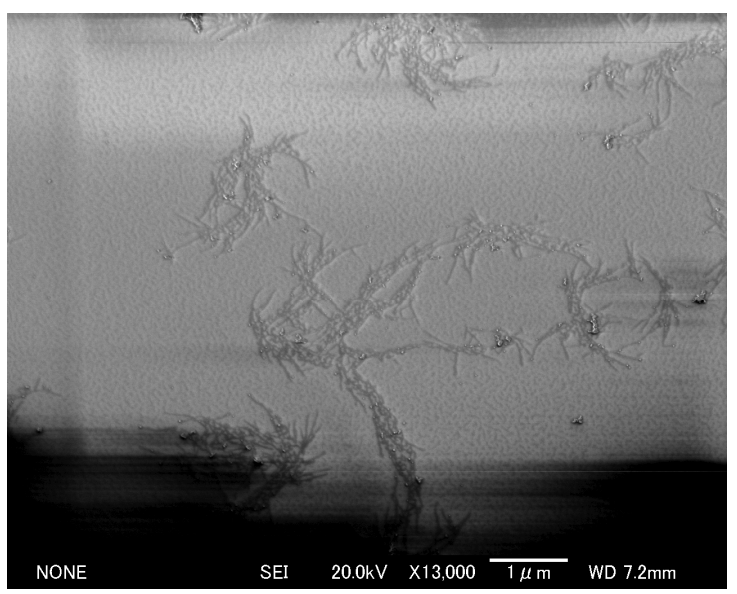

b)

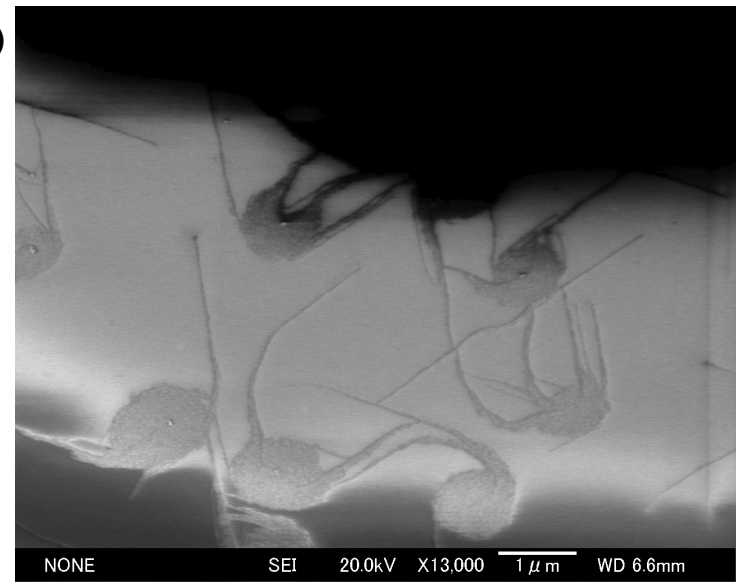

d)

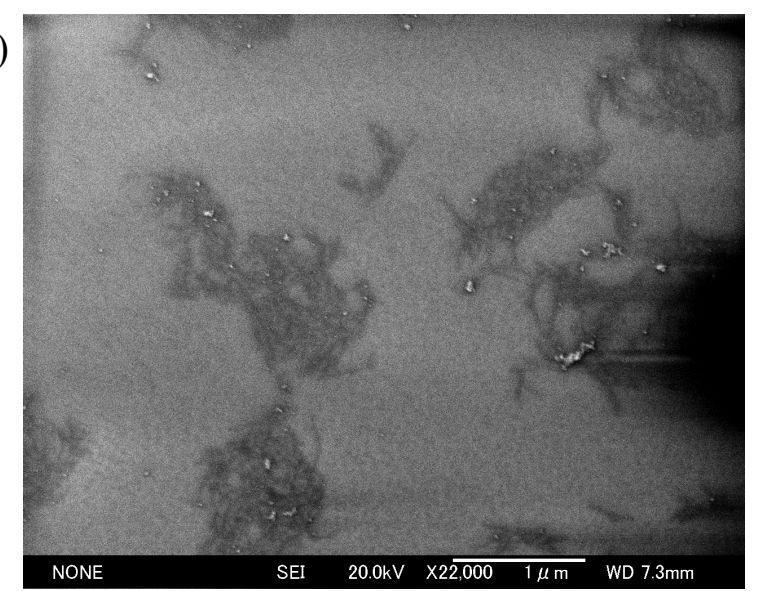

Figure S4. SEM images of LB films (a and b) II $\left(c_{\mathrm{Au}}=1 \times 10^{-6} \mathrm{M}\right)$ and (c and d) III $\left(c_{\mathrm{Au}}=1 \times 10^{-5} \mathrm{M}\right)$. 


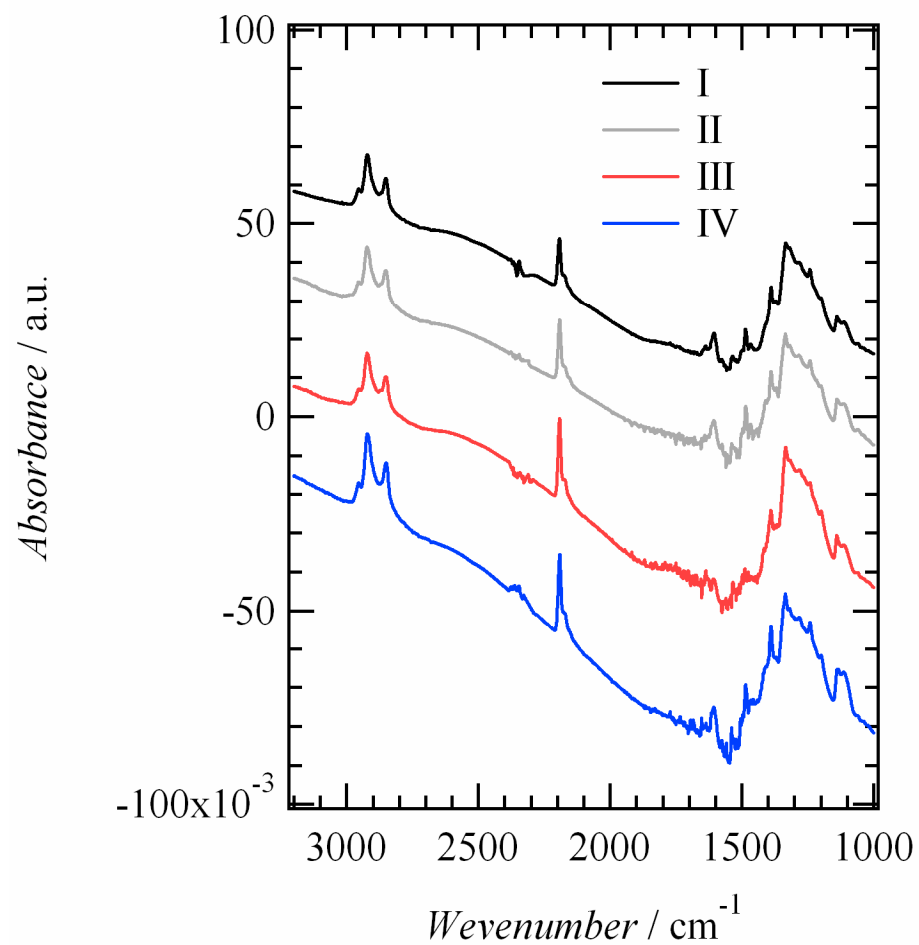

Figure S5. Transmittance IR spectra of LB films (i) I, (ii) II, (iii) III, and (iv) IV. Forty-layer LB films on $\mathrm{CaF}_{2}$ substrate were measured.
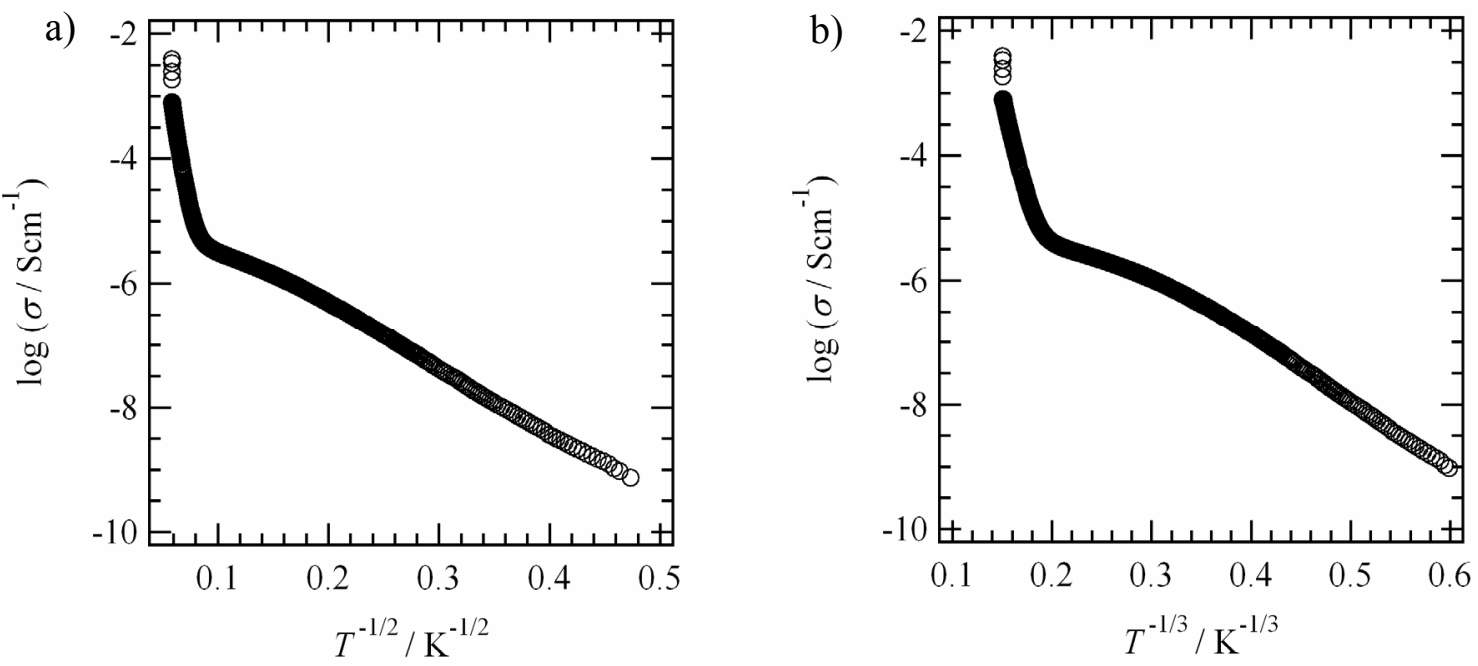


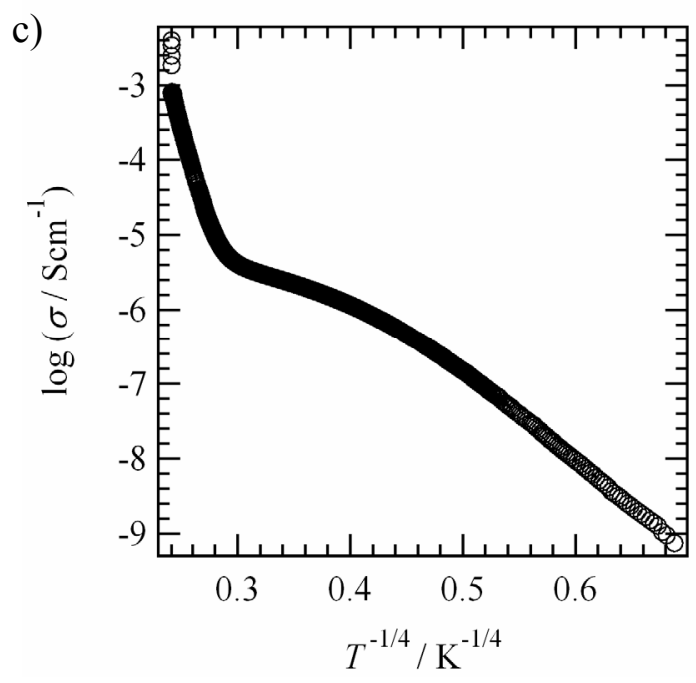

Figure S6. Logarithmic electrical conductivity $(\log \sigma)$ vs. a) $T^{-1 / 2}$, b) $T^{-1 / 3}$, and c) $T^{-1 / 4}$ plots for LB films IV, which correspond to 1D, 2D, and 3D VRH model. When the VRH model was consistent with the conducting behaviors, the liner relation between the $\log \sigma$ and $T^{-1 / \alpha}(\alpha=2,3$, and 4$)$ should be appeared.

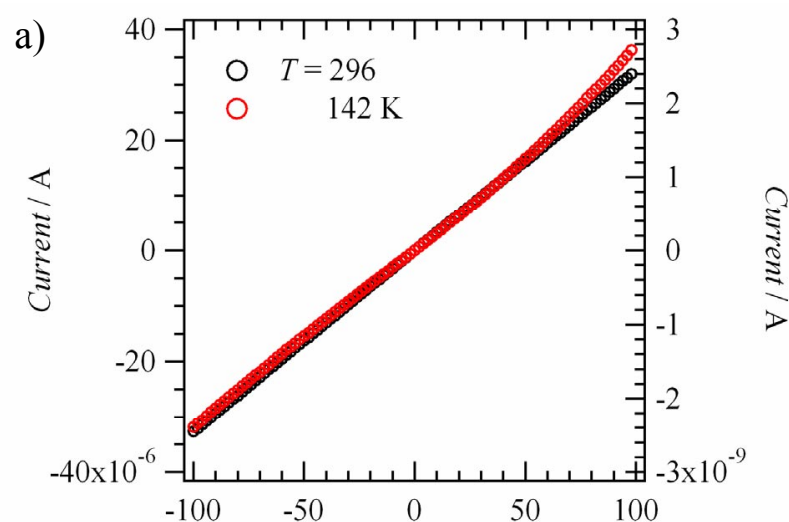

Bias / V

c)

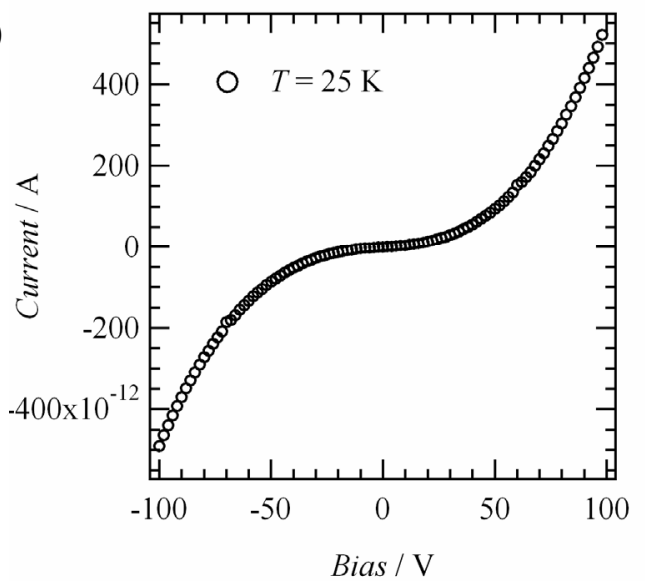

b)

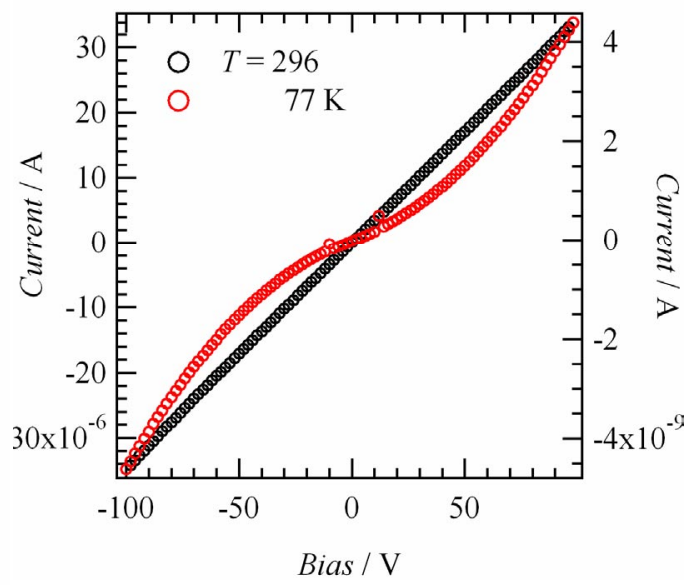

d)

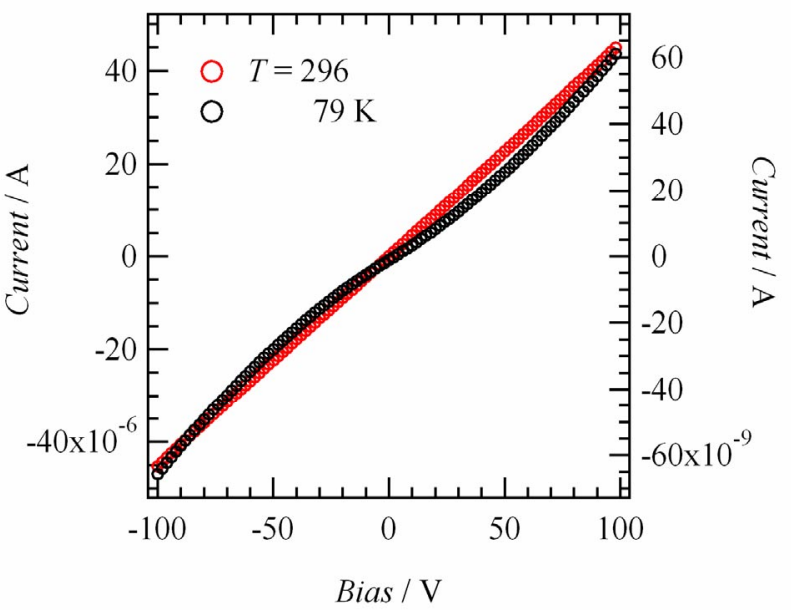



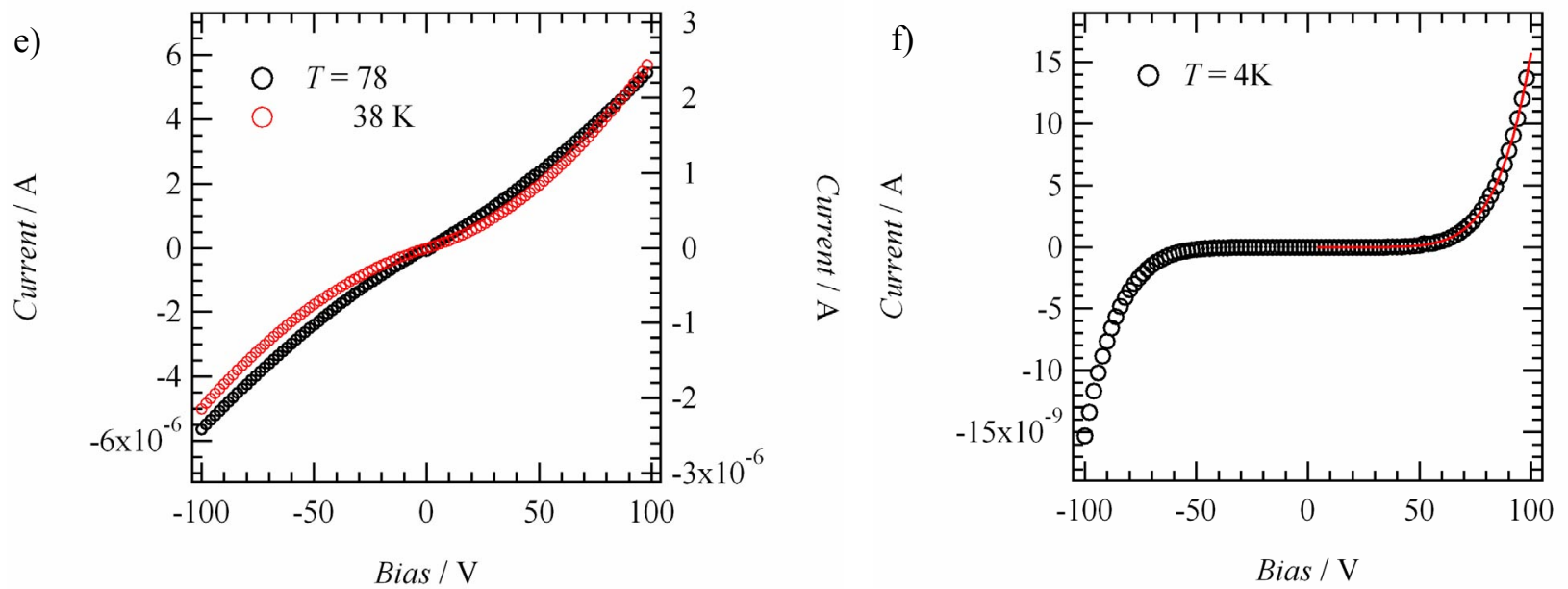

Figure S7. (a) $I$ vs. $V$ plots of LB film II at 296 and $142 \mathrm{~K}$. (b) $I$ vs. $V$ plots of LB film III at 296 and $77 \mathrm{~K}$. (c) $I$ vs. $V$ plots of LB film III at $25 \mathrm{~K}$. (d) $I$ vs. $V$ plots of LB film IV at 296 and 79 K. (e) $I$ vs. $V$ plots of LB film $\mathbf{V}$ at 78 and $38 \mathrm{~K}$. (f) $I$ vs. $V$ plots of LB film $\mathbf{V}$ at $4 \mathrm{~K}$ 

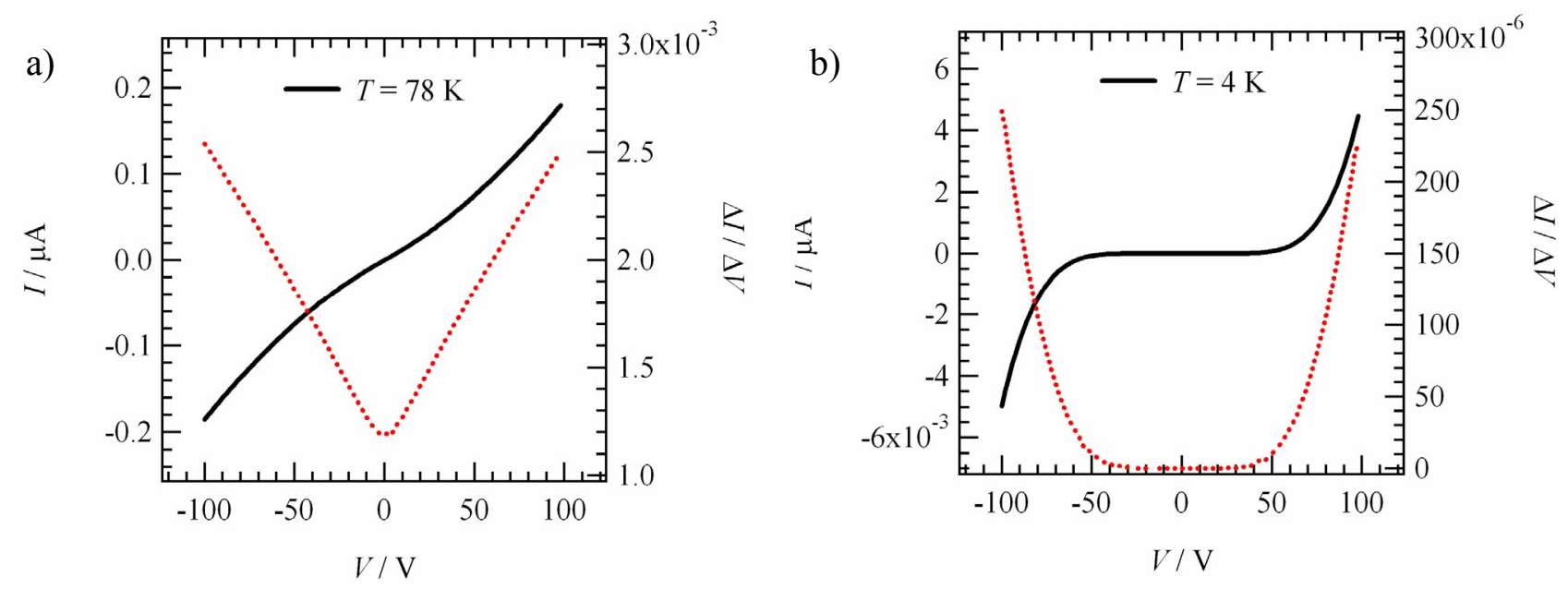

Figure S8. The voltage derivative of current $(\Delta I / \Delta V)$ plots of LB film IV at a) 78 and b) $4 \mathrm{~K}$.

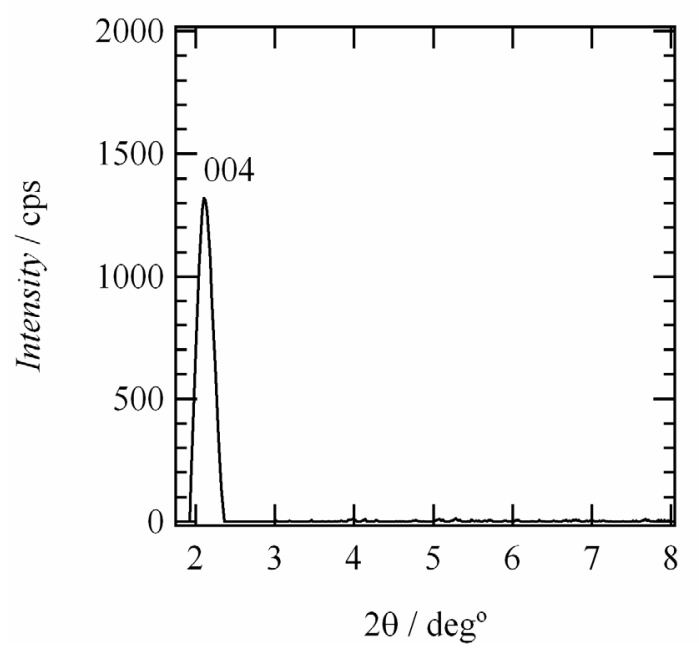

Figure S9. X-ray reflection diffraction (XRD) profile of LB film IV on quartz substrate. 40-layer LB films for the XRD measurements were deposited by the horizontal-lifting method. XRD were measured using a Rigaku RINT-2000 diffractometer with $\mathrm{Cu}-\mathrm{K} \alpha(\lambda=1.5418 \AA)$ radiation from a graphite monochromator in a $2 \theta$ scanning range from 1.00 to $10.0^{\circ}$ with an interval of $0.02^{\circ}$ and a scan speed of $2.00^{\circ} \mathrm{min}^{-1}$. The reflection was corresponded to the periodicity of $16.8 \mathrm{~nm}$ for (004) reflection index. 
a)

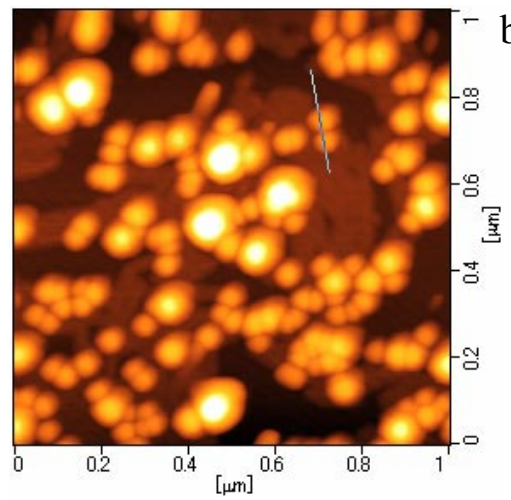

))

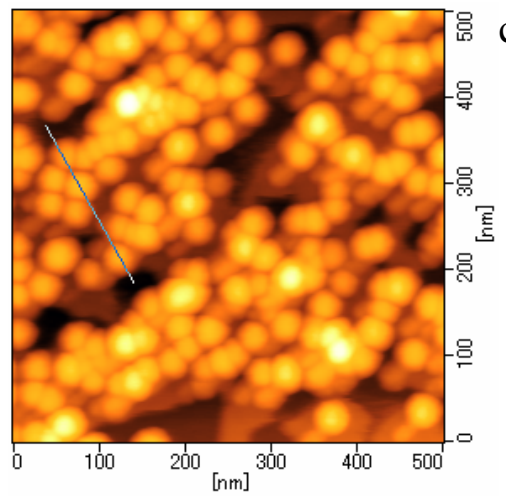

c)

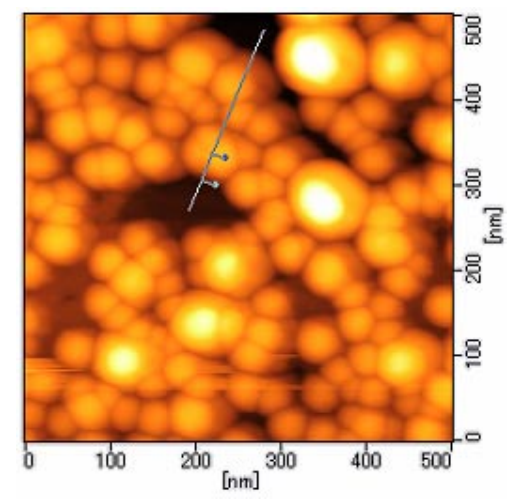

Figure S10. AFM images of the forty-layer LB films a) II, b) III, and c) IV on PET film Au nanoparticles were observed as bright spots. AFM images were taken by a) $1.0 \times 1.0, \mathrm{~b}) 0.5 \times 0.5$, and c) $0.5 \times 0.5 \mu \mathrm{m}^{2}$ scanning area. The forty-layer LB films were fabricated by the horizontal-lifting method. 
a)

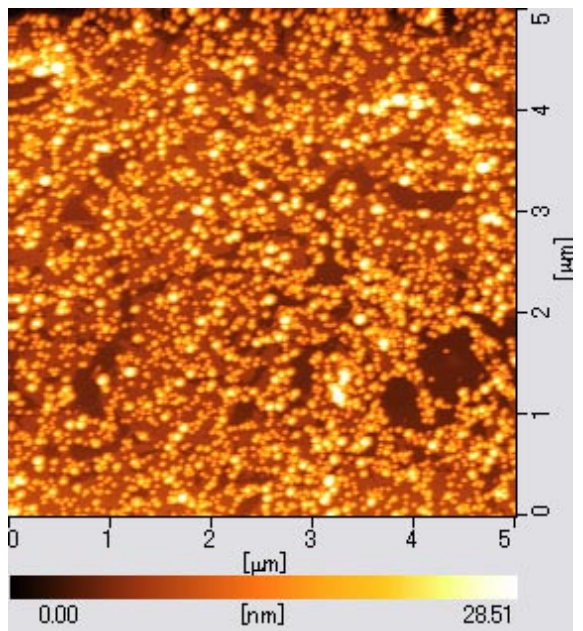

c)

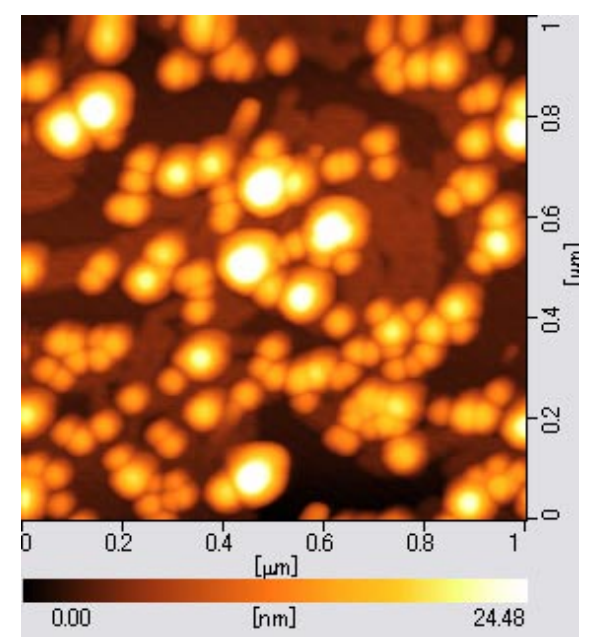

b)

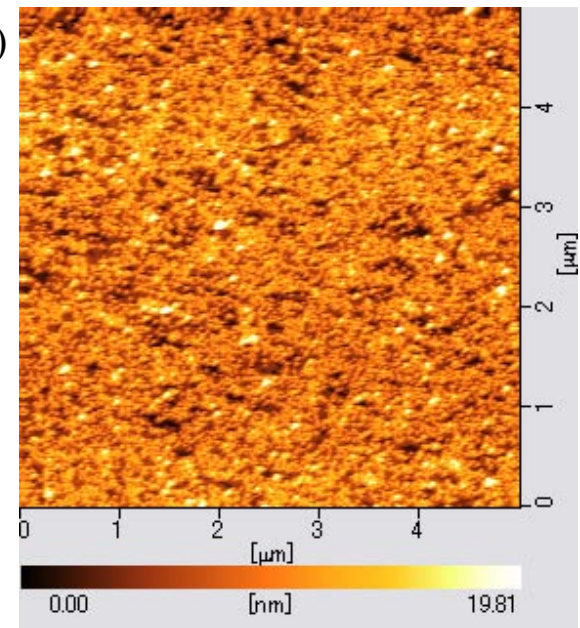

d)

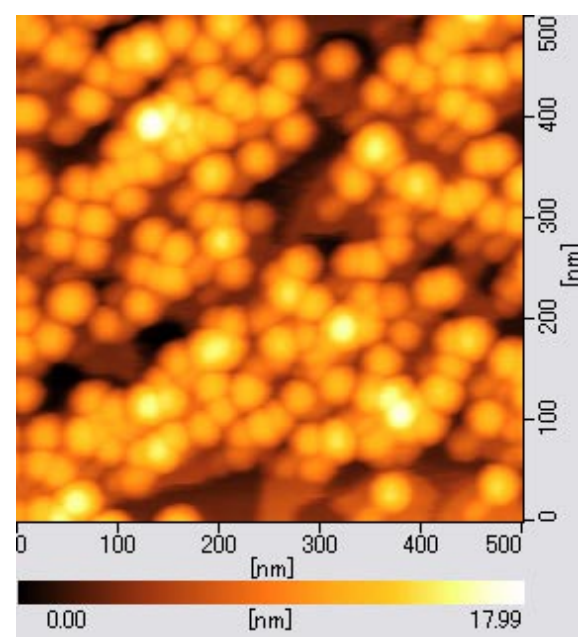

Figure S11. AFM images of the LB films a) IV $\left(5 \times 5 \mu \mathrm{m}^{2}\right)$, b) IV $\left(1 \times 1 \mu \mathrm{m}^{2}\right)$, c) $\mathbf{V}\left(5 \times 5 \mu \mathrm{m}^{2}\right)$, and c) $\mathbf{V}\left(0.5 \times 0.5 \mu \mathrm{m}^{2}\right)$ on mica. Gold nanoparticles were observed as bright spots. The one-layer LB films were fabricated by the horizontal-lifting method on hydrophobic mica surface (five layer deposition of cadmium arachidate). 